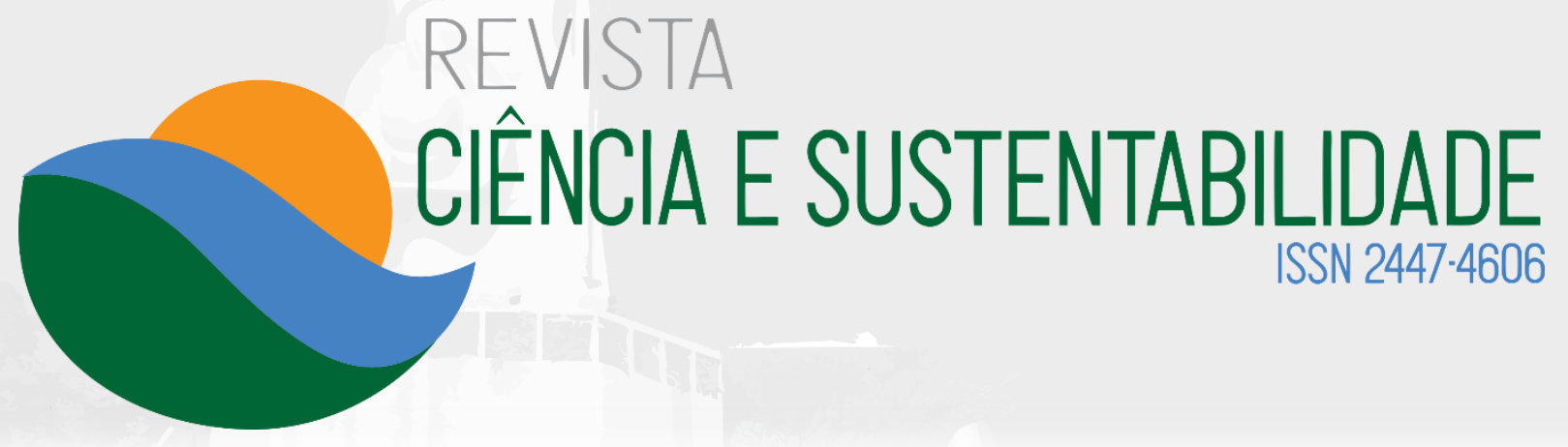

\title{
Regulamentação dos grandes geradores de resíduos sólidos em Juazeiro do Norte-CE: avaliação e propostas
}

\author{
Regulation of large solid waste generators in Juazeiro do \\ Norte-CE: evaluation and proposals
}

\author{
Brenda Tamires Conceição e Sá \\ Instituto Federal de Educação, Ciências e \\ Tecnologias do Ceará (IFCE), campus \\ Juazeiro do Norte. Graduada em \\ Engenharia Ambiental pelo Instituto \\ Federal de Educação, Ciência e \\ Tecnologia do Ceará, Brasil (2018). \\ E-mail: brendasa.tc@gmail.com
}

\section{Joelma Lima Oliveira}

Instituto Federal de Educação, Ciência e Tecnologia do Ceará (IFCE), campus Juazeiro do Norte. Tecnóloga em Saneamento Ambiental pelo IFCE. Mestre em Engenharia Civil pela UFC (2014).

Docente do Departamento de Engenharia Ambiental e Sanitária do IFCE- Campus Juazeiro do Norte. E-mail:

joelma.oliveira@ifce.edu.br

\section{José Eraldo Oliveira Costa}

Associação de Gestores Ambientais do Estado do Ceará - AGACE. Bacharel em Direito pela URCA.

E-mail: eraldooliveirajnce@yahoo.com.br

\section{Yannice Tatiane da Costa Santos Instituto Federal de Educação, Ciência e Tecnologia do Ceará (IFCE), campus Juazeiro do Norte. Tecnóloga em Gestão Ambiental pelo CEFET-CE. Mestra em Programa de Pós-gradução em Engenharia Sanitária pela Universidade}

RESUMO

Motivando-se pelos questionamentos levantados através do Conselho Municipal de Defesa do Meio Ambiente (COMDEMA) acerca da possibilidade do município de Juazeiro do Norte compartilhar a responsabilidade de coleta, transporte e destinação ambientalmente adequada dos resíduos com os grandes geradores, o estudo objetivou avaliar os mecanismos legais, baseados nas legislações nacionais existentes, bem como a própria realidade de geração de resíduos do município, na busca de sugerir propostas para compor uma regulamentação que se adequem aos anseios das partes envolvidas. Desta forma, analisaram-se as legislações em execução nos municípios do Distrito Federal (DF), São Paulo (SP), Belém (PA), Santos (SP) e Fortaleza (CE), bem como as do município em estudo e Estudos Ambientais pertinentes. Constatou-se que Juazeiro do Norte é carente de legislações que abordem a temática de Resíduos Sólidos (RS) de forma mais específica e isso reflete diretamente nos costumes populacionais em acondicionamentos e descartes incorretos desses resíduos. Construiu-se uma série de sugestões com vistas à melhor eficiência do Sistema de Gestão Municipal dos RS incluindo um quadro referencial de dados qualiquantitativos de resíduos gerados por determinados tipos de empreendimentos considerando seus respectivos portes. A adesão a esse tipo de política aliada à obrigação de implementação da coleta seletiva nessas unidades é de extrema importância para inverter as prioridades de investimento dos municípios focalizando na não 
Regulamentação dos grandes geradores de resíduos sólidos em Juazeiro do Norte-CE: avaliação e propostas

Federal do Rio Grande do Norte, Brasil(2009)/Docente do Departamento de Engenharia Ambiental e Sanitária do IFCE- Campus Juazeiro do Norte. E-mail: yannicesantos@yahoo.com.br

Recebido em: 30/08/2018 I Aceito em: 19/11/2018 geração, redução, reutilização e reciclagem, e em último caso a disposição final.

Palavras-chave: Gestão Integrada de Resíduos Sólidos. Coleta Seletiva. Grandes Geradores.

\section{ABSTRACT}

Motivated by the questions raised by the Municipal Environmental Defense Council (COMDEMA) about the possibility of the municipality of Juazeiro do Norte shares responsibility for collecting, transporting and disposing of the environmentally sound waste with large generators, the study aimed to evaluate the legal mechanisms, based on existing national legislation, as well as the actual reality of municipal waste generation, in the search of suggest proposals to make a regulation that suits the wishes of the parties involved. In this way, we analyzed the legislation in the municipalities of the Federal District (DF), São Paulo (SP), Belém (PA), Santos (SP) and Fortaleza (CE), as well as those of the municipality under study and relevant Environmental Studies. It was found that Juazeiro do Norte is lacking on legislation that addresses the issue of solid waste (SW) in a more specific way and this reflects directly in the population customs in packaging and incorrect discarding of this waste. A series of suggestions was built with a view to improving the efficiency of the Municipal SW Management System, including a reference framework of qualitative waste data, generated by certain types of enterprises, considering their respective sizes. Adherence to this type of policy coupled with the obligation to implement the selective collection in these units is extremely important to reverse the investment priorities of the municipalities, focusing on non-generation, reduction, reuse and recycling, and ultimately final disposal.

Keywords: Integrated Solid Waste Management. Selective collect. Large Generators. 


\title{
1 INTRODUÇÃO
}

O Gerenciamento de Resíduos Sólidos (RS) instituído pela Lei n 12.305/2010 - Política Nacional de Resíduos Sólidos (PNRS) consiste em um conjunto de ações exercidas, direta ou indiretamente, nas etapas de coleta, transporte, transbordo, tratamento e destinação final ambientalmente adequada dos RS e disposição final ambientalmente adequada dos rejeitos (BRASIL, 2010).

Todos os estabelecimentos sejam domiciliares, comerciais ou industriais, tem sua parcela de responsabilidade e precisam criar ferramentas para dispor de forma adequada e ambientalmente correta os resíduos gerados. Logo, a PNRS introduz um novo conceito de responsabilidade compartilhada pelo ciclo de vida do produto:

\begin{abstract}
Um conjunto de atribuições individualizadas e encadeadas dos fabricantes, importadores, distribuidores e comerciantes, dos consumidores e dos titulares dos serviços públicos de limpeza urbana e de manejo dos resíduos sólidos, para minimizar o volume de resíduos sólidos e rejeitos gerados, bem como para reduzir os impactos causados à saúde humana e à qualidade ambiental decorrentes do ciclo de vida dos produtos, nos termos desta Lei (BRASIL, 2010).
\end{abstract}

Eximindo, assim, a total responsabilidade antes idealizada como sendo somente do Poder Público.

No Brasil, a Lei no 11.445/2007 - Política Nacional de Saneamento Básico (PNSB), em seu art. 29, Inciso II, prevê que para assegurar a sustentabilidade econômico-financeira dos serviços públicos de saneamento básico, como a Limpeza Urbana e Manejo de RS, devem ser aplicadas taxas ou tarifas e outros preços públicos para sua execução (BRASIL, 2007).

Segundo Machado (2014), atualmente, países como Alemanha, Bélgica, Estados Unidos, Finlândia, França, Holanda, Inglaterra, Itália, Luxemburgo e Nova Zelândia cobram pelos serviços de coleta de resíduos. E, em 1995, o Economista Jacques Demajorovic (1995) já tinha observado que a introdução de ferramentas econômicas nas políticas de gestão ambiental exerce um impacto significativo na eficiência do gerenciamento de RS, principalmente, quando aliada a programas de coleta seletiva. 
No cenário estadual, o Ceará através da Secretaria de Meio Ambiente (SEMA), em 06 de dezembro de 2017, entregou o Plano de Coleta Seletiva aos municípios envolvidos - 23 municípios que compõem a Bacia do Rio Salgado - inclusive Juazeiro do Norte-CE. Desta forma, desde março de 2017, com o início das discussões acerca da elaboração desse plano, os gestores públicos de Juazeiro do Norte, competentes a esse setor, visaram à necessidade de elaborar uma regulamentação para os Grandes Geradores de Resíduos Sólidos (GGRS), com vistas à melhor atender as legislações e com uma perspectiva de futuro na implementação desse Plano.

No município, essa regulamentação foi solicitada por uma demanda do Conselho Municipal de Defesa do Meio Ambiente (COMDEMA) - órgão central do Sistema Municipal de Meio Ambiente (SISMAM) - que, ao participar das discussões acerca do referido Plano, introduziu questionamentos sobre a produção desses geradores previamente caracterizados como empreendimentos Comerciais ou de Prestação de Serviço de porte Grande a Excepcional, por exemplo, Casas de Show, Restaurantes, Supermercados de Atacado ou Varejo, dentre outros, que contribuem majestosamente com a quantidade de RS destinados a coleta pública municipal.

Considerando a possibilidade de o município repassar a responsabilidade de coleta, transporte e destinação ambientalmente adequada aos GGRS, tendo em vista o expressivo volume gerado, abriu-se para essa temática o estudo e discussões de quais procedimentos técnicos, logísticos e, principalmente, legais devem ser instituídos para regulamentar essa prática.

De forma a colaborar com essa discussão, o presente estudo objetivou avaliar os mecanismos legais, baseados nas legislações nacionais existentes, bem como a própria realidade de geração dos resíduos do município de Juazeiro do Norte com a finalidade de sugerir propostas para compor essa regulamentação, que se adequem aos anseios de ambas as partes envolvidas. 


\section{METODOLOGIA}

\section{1 Área de Estudo}

O município de Juazeiro do Norte (CE) localizado na Mesorregião Sul Cearense (Figura 01), constituindo a Região Metropolitana do Cariri (RMC) se destaca em desenvolvimento econômico e demográfico em relação aos demais municípios dessa região. Segundo IBGE (2010), é o $3^{\circ}$ município mais populoso do estado do Ceará, com uma população de 249.939 habitantes, ficando atrás apenas de Caucaia e Fortaleza, respectivamente.

Figura 1 - Localização do município de Juazeiro do Norte (CE)

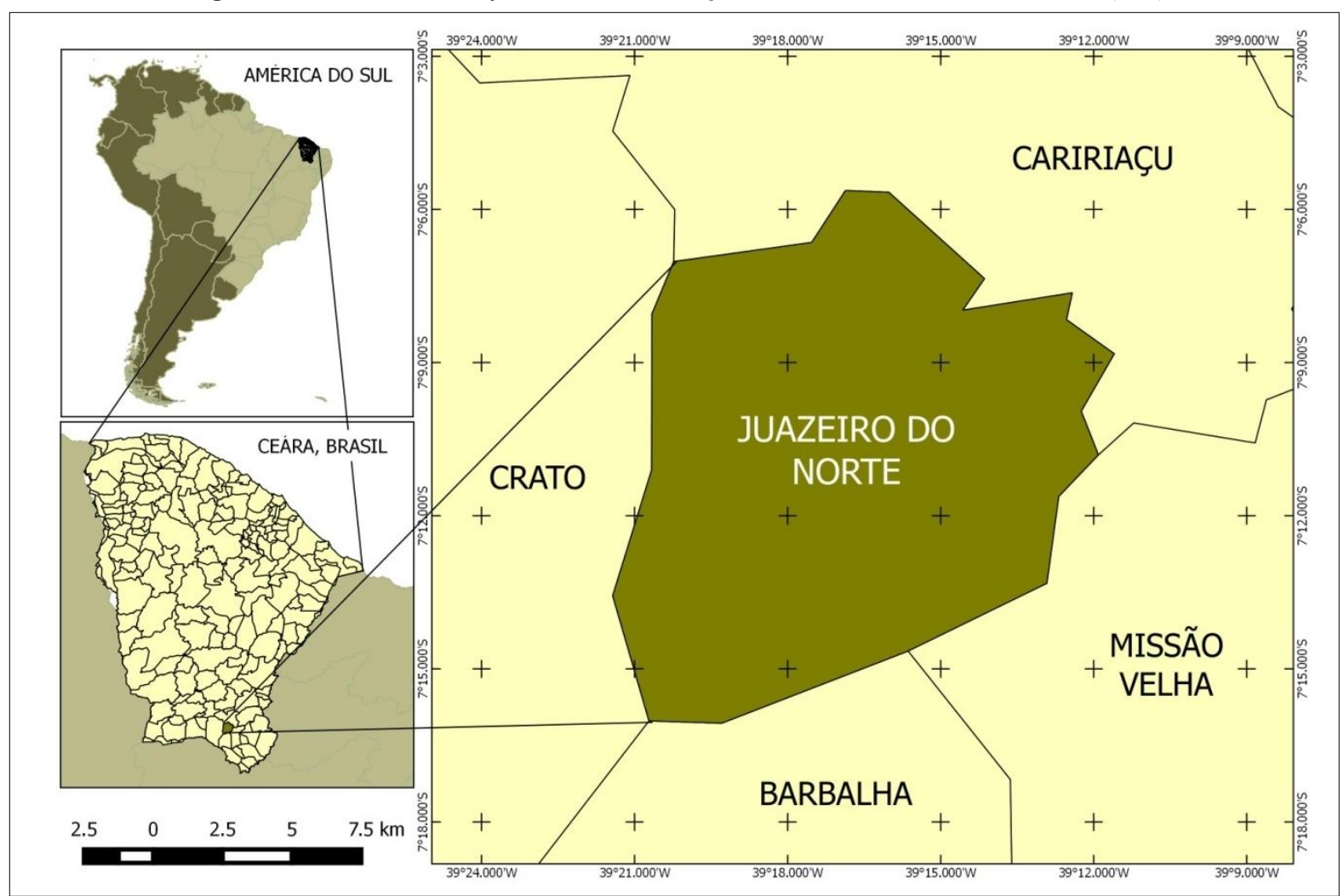

Fonte: Autor (2018). Software QGis 2.2.0 - Valmiera.

Este ocupa ainda a posição de quinta maior economia do estado possuindo grandes centros de artesanatos e cordel e movimentando algumas das maiores romarias do país. Além disso, possui o maior pólo calçadista do Nordeste e um dos maiores pólos acadêmicos da região. A cidade é conhecida como "Cidade da Fé", "Metrópole do Cariri", "Juá" e "Terra do Padim Ciço". (LEITE, 2017). 


\subsection{Procedimento metodológico}

Essa pesquisa se utilizou de levantamento bibliográfico de autores que dissertam e argumentam sobre o Gerenciamento de RS na atualidade, bem como das legislações brasileiras vigentes que regulamentam e instituem os paradigmas dessa gestão, de uma forma geral, a níveis de governo Federais, Estaduais e Municipais.

Especificamente, foram analisadas as legislações e suas alterações posteriores em execução nos municípios do Distrito Federal (DF), São Paulo (SP), Belém (PA), Santos (SP) e Fortaleza (CE) que instituem a responsabilidade dos GGRS relativa ao gerenciamento dos $\mathrm{RS}$ gerados, com vistas a adequá-las a realidade juazeirense. E a legislação do município em estudo, Decreto n 226/2016, que, preliminarmente, já institui limites para coleta regular pública dos Resíduos Sólidos de Construção Civil (RSCC) e resultantes da Poda de Árvores e Limpeza de Jardins.

A coleta de dados consistiu no estudo de bibliografias voltadas para o Sistema local de Gestão de RS através de Artigos Científicos na base de dados do Periódico da CAPES (acesso pelo sistema CAFE), legislações do município em estudo, vigentes, junto a documentos fornecidos pelos órgãos municipais ambientais competentes, como Estudos e Planos existentes, dentre eles o Estudo Gravimétrico - Diagnóstico de RS do município de Juazeiro do Norte (2016), Plano de Gestão Integrada de RS de São Paulo (PGIRSSP, 2014), Plano Municipal de Gestão Integrada de RS de Fortaleza (PMGIRSF, 2012) e Minuta do Plano Distrital de Gestão Integrada de RS (PDGIRS, 2017).

Para construção de uma referência no quantitativo de geração de resíduos nos empreendimentos de Juazeiro do Norte (CE), analisou-se um total de cinco Planos de Gerenciamento de Resíduos Sólidos (PGRS) aprovados e disponibilizados pela AMAJU, órgão ambiental licenciador e fiscalizador.

Já no que diz respeito à estimativa dos resíduos gerados em empreendimentos condominiais residenciais, utilizou-se dados de Geração Per capita de RS Urbanos para o município de Juazeiro do Norte, de 0,82 kg/hab/d, adaptado através do Diagnóstico de RS de Juazeiro do Norte (2016), considerando uma população residente de três pessoas por unidade habitacional. Para estimar o valor em volume diário, aplicou-se o Peso Específico encontrado no estudo de Rabelo 
et al. (2015) para condomínios verticais em $183 \mathrm{~kg} / \mathrm{m}^{3}$ e para condomínios horizontais $191 \mathrm{~kg} / \mathrm{m}^{3}$. As amostras foram aleatórias, escolhendo-se três condomínios residenciais verticais e dois horizontais, calculando-se a média final de ambas as classes.

E por fim, para as instituições de ensino superior, em decorrência da inexistência de PGRS que abrangesse toda a sua estrutura, optou-se por verificar in loco o volume de resíduos acondicionados em determinado dia da semana, obtendose o resultado final a partir da medição do volume ocupado, no dia, na "casinha" de acondicionamento dos resíduos gerados e, através de perguntas aos servidores responsáveis por esse setor quanto à constância na geração do volume encontrado e frequência de coleta - três vezes por semana - realizada pelo serviço público de limpeza urbana.

\section{RESULTADOS E DISCUSSÃO}

\subsection{Perspectiva Nacional dos GGRS}

Em análise as legislações existentes dos municípios de São Paulo - SP, Fortaleza - CE, Brasília - DF, Belém - PA, Juazeiro do Norte - CE e Santos - SP que instituem regulamentações específicas para empreendimentos GGRS, observou-se diferentes definições quanto as classificações dos tipos de resíduos, e principalmente, nos aspectos de volume ou quilograma diário que caracterize um empreendimento ou estabelecimento como tal, conforme pode ser observado no Quadro 01. 
Regulamentação dos grandes geradores de resíduos sólidos em Juazeiro do Norte-CE: avaliação e propostas

Quadro 01 - Comparativo de legislações existentes que regulamentam os GGRS quanto ao tipo e à produção

\begin{tabular}{|c|c|c|c|c|c|c|}
\hline & & \multirow[b]{2}{*}{$\begin{array}{c}\text { GGR } \\
S \\
(K g / \\
d) \\
\end{array}$} & \\
\hline & Município & $\begin{array}{l}\text { Densidade } \\
\text { Demográfica } \\
2 \text { (hab/km²) }\end{array}$ & $\begin{array}{c}\text { Geração per } \\
\text { capita de RSU } \\
\text { (kg/hab.d) }\end{array}$ & $\begin{array}{c}\text { Classificação de } \\
\text { RS }^{8}\end{array}$ & & $\begin{array}{l}\text { GGR } \\
S \\
(L / d)\end{array}$ \\
\hline \multirow{4}{*}{$\begin{array}{l}\text { Lei } n^{\circ} 13.478 \text {, } \\
\text { de } 30 \text { de } \\
\text { dezembro de } \\
2002, \text { com } \\
\text { suas } \\
\text { alterações } \\
\text { posteriores } \\
\\
\text { E em conjunto } \\
\text { com a Lei no } \\
14.973, \text { de } 11 \\
\text { de setembro } \\
\text { de } 2009\end{array}$} & \multirow[b]{4}{*}{$\begin{array}{c}\text { São } \\
\text { Paulo - } \\
\text { SP }\end{array}$} & \multirow[b]{4}{*}{$7.398,26$} & \multirow[b]{4}{*}{$1,1^{3}$} & $\begin{array}{c}\text { Classe I, exceto } \\
\text { RSS }\end{array}$ & \multicolumn{2}{|c|}{$\mathrm{RI}$} \\
\hline & & & & Classe II - A & - & $\stackrel{>}{200}$ \\
\hline & & & & Classe II - B & $>50$ & - \\
\hline & & & & $\begin{array}{l}\text { Classe II - } \\
\text { Condomínios de } \\
\text { edifícios não } \\
\text { residenciais ou } \\
\text { de uso misto }\end{array}$ & - & $\geq$ \\
\hline \multirow{3}{*}{$\begin{array}{l}\text { Lei } n^{\circ} 10.340 \text {, } \\
\text { de } 28 \text { de abril } \\
\text { de } 2015 .\end{array}$} & \multirow{3}{*}{$\begin{array}{l}\text { Fortalez } \\
a-C E\end{array}$} & \multirow{3}{*}{$7.786,44$} & \multirow{3}{*}{$0,66^{4}$} & Classe II & - & $\geq$ \\
\hline & & & & RSCC & - & $\geq 50$ \\
\hline & & & & RSS & \multicolumn{2}{|c|}{$\mathrm{RI}$} \\
\hline \multirow{3}{*}{$\begin{array}{l}\text { Decreto } \\
83.021 \text { de } 19 \\
\text { de setembro } \\
\text { de } 2015 .\end{array}$} & \multirow[b]{3}{*}{$\begin{array}{l}\text { Belém - } \\
\text { PA }\end{array}$} & \multirow[b]{3}{*}{$1.315,26$} & & Classe II - A & - & 200 \\
\hline & & & & RSCC & $>50$ & - \\
\hline & & & & $\begin{array}{l}\text { Classe II - } \\
\text { Condomínios de } \\
\text { edifícios não } \\
\text { residenciais ou } \\
\text { de uso misto }\end{array}$ & - & $\underset{1000}{\geq}$ \\
\hline \multirow{2}{*}{$\begin{array}{l}\text { Decreto } n^{\circ} \\
226, \text { de } 21 \text { de } \\
\text { janeiro de } \\
2016 .\end{array}$} & \multirow[b]{2}{*}{$\begin{array}{l}\text { Juazeiro } \\
\text { do } \\
\text { Norte-CE }\end{array}$} & \multirow[b]{2}{*}{$1.004,45$} & \multirow[b]{2}{*}{$0,82^{5}$} & $\begin{array}{l}\text { RSCC/ Bens } \\
\text { Móveis } \\
\text { inservíveis }\end{array}$ & \multicolumn{2}{|c|}{$\mathrm{RI}$} \\
\hline & & & & $\begin{array}{l}\text { Resíduos de } \\
\text { Podas de } \\
\text { Árvores e } \\
\text { Limpeza de } \\
\text { Jardins } \\
\end{array}$ & - & 300 \\
\hline $\begin{array}{l}\text { Decreto } n^{\circ} \\
37.568, \text { de } 25 \\
\text { de agosto de } \\
2016 .\end{array}$ & \multirow{2}{*}{$\begin{array}{l}\text { Distrito } \\
\text { Federal } \\
\text { - DF }\end{array}$} & \multirow{2}{*}{444,66} & \multirow{2}{*}{$0,88^{6}$} & $\begin{array}{l}\text { Classe II - } \\
\text { Exceto Inertes }\end{array}$ & - & $\stackrel{>}{120}$ \\
\hline $\begin{array}{l}\text { Lei } n^{\circ} 4.704 \\
\text { de } 20 \text { de } \\
\text { dezembro de } \\
2011\end{array}$ & & & & $\begin{array}{l}\text { RSCC e Resíduos } \\
\text { Volumosos }\end{array}$ & \multicolumn{2}{|c|}{ RI } \\
\hline $\begin{array}{l}\text { Lei } \\
\text { Complementar } \\
n^{\circ} 952 \text {, de } 30\end{array}$ & $\begin{array}{l}\text { Santos - } \\
\text { SP }\end{array}$ & $1.494,26$ & $1,7^{7}$ & $\begin{array}{c}\text { Classe II - } \\
\text { Apenas } \\
\text { Recicláveis e/ou } \\
\text { Orgânicos }\end{array}$ & $\stackrel{>}{120}$ & 200 \\
\hline
\end{tabular}




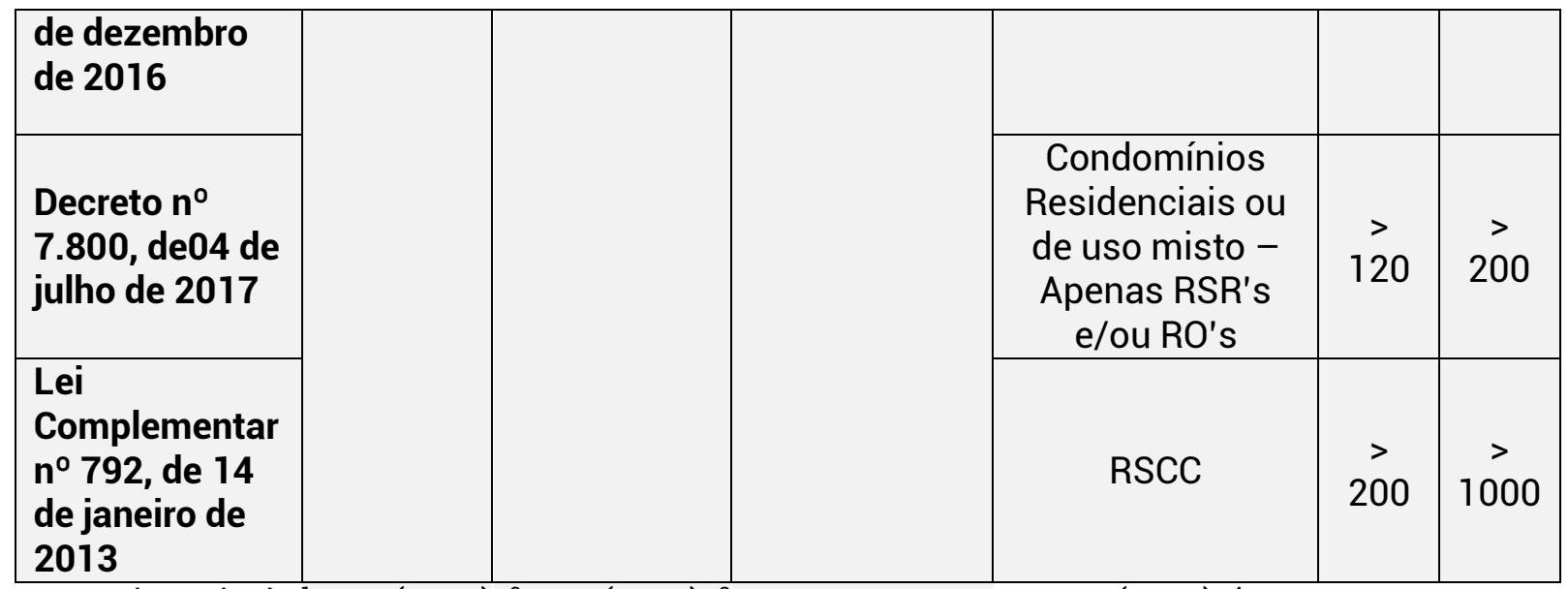

Fonte: Adaptado de ${ }^{1}$ IBGE (2017); ${ }^{2}$ IBGE (2010); ${ }^{3}$ Para o ano 2012 - PGIRS (2014); ${ }^{4}$ Para o ano 2011 PMGIRS (2012); ${ }^{5}$ Diagnóstico de Resíduos Sólidos (2016); ${ }^{6}$ Para o ano 2015 - Minuta do PDGIRS (2017); ${ }^{7}$ PGIRSMS (2011-2012); ${ }^{8}$ NBR 10004:2004 ABNT.Nota: RI - Responsabilidade Integral de qualquer Quantidade ou Volume gerado; RSR's - Resíduos Secos Recicláveis; RO's - Resíduos Orgânicos; RSU - Resíduos Sólidos Urbanos.

A legislação do município de São Paulo, Lei n 13.478/2002 e suas alterações posteriores, instituem não somente diretrizes e determinações para os GGRS, mas para todo o sistema de limpeza pública do município e apresenta-se com uma abordagem diferenciada, uma vez que compreende a Classe I - Perigosos, especificamente, os Resíduos de Serviços de Saúde (RSS), na coleta de Regime Público.

Do mesmo modo ocorre para os domicílios residenciais e não residenciais que não se enquadrarem em grandes geradores, determinando que o poder público realize a coleta de seus $\mathrm{RS}$ mediante a cobrança da taxa.

Nessa, é previsto um fator de Correção Social denominado por "K" que constitui a equação utilizada para calcular o valor individual da Taxa de Resíduos Sólidos Domiciliares (TRSD), o qual será sempre inferior a 1 para os munícipes usuários que aderirem aos programas sociais de triagem de materiais recicláveis e coleta seletiva de RS por cooperativas de catadores, bem como à instituições de ensino, sejam elas públicas ou privadas, que incentivarem a coleta seletiva através de programas de educação ambiental e implementarem Pontos de Entrega Voluntária (PEV) em seus estabelecimentos.

Tal incentivo é necessário à construção da sustentabilidade ambiental e socioeconômica dos serviços de Limpeza Pública municipal, uma vez que com o 
aumento demográfico das cidades e as recentes exigências da PNRS, o desafio deixou de ser apenas a coleta dos RS urbanos, mas, principalmente, em dar a devida destinação final ambientalmente adequada a esses.

Em seu Art. 139, nos incisos I e II, definem-se então os GGRS como os proprietários, possuidores ou titulares de estabelecimentos públicos, institucionais, de prestação de serviços, comerciais e industriais, entre outros, geradores de resíduos sólidos caracterizados como resíduos da Classe 2, pela NBR 10004:2004 ABNT, em volume superior a 200 litros diários e àqueles geradores de resíduos sólidos de entulhos, terra e materiais de construção, com massa superior a 50 quilogramas diários.

Em 2009, através da Lei $n^{\circ}$ 14.973, que dispõe sobre a organização de sistemas de coleta seletiva nos GGRS do município de São Paulo, incluiu-se nesta definição os condomínios de edifícios não residenciais ou de uso misto.

Semelhantemente, o Decreto 83.021/2015 do município de Belém do Pará, estabelece os mesmos parâmetros da Paulista, introduzindo um diferencial a essas legislações quanto aos condomínios não residenciais ou mistos, uma vez que as demais legislações estudadas não os compreendem. Contudo, vale destacar que esse tipo de empreendimento acomete diversos impactos ao meio ambiente, tendo em vista que geram um grande volume de RS por área territorial.

Segundo o PGIRSSP (2014) existem cerca de 8 mil GGRS indiferenciados cadastrados, servidos por 60 empresas autorizatárias cadastradas na Autoridade Municipal de Limpeza Urbana (AMLURB) para o processo de coleta, transporte e destinação final dos resíduos. O mesmo prioriza a fiscalização dos PGRS quanto às indicações dos fluxos de recuperação dos Resíduos Orgânicos (RO's) com vistas a eliminar sua disposição em aterros e, ainda, a programar coleta seletiva na origem, logística reversa e destinação adequada das lâmpadas usadas.

Relata, ainda, a iniciativa do gerenciamento de resíduos provenientes de feiras livres através do Programa Feira Limpa, implantado e desenvolvido em 2001, incentivando a coleta seletiva dos resíduos gerados por essas atividades segregando os restos de frutas, legumes e verduras das madeiras, palhas e coco verde além de outros materiais inservíveis e dos Resíduos Secos Recicláveis (RSR's). 
Se tratando do município de Fortaleza (CE), a Lei No 10.340/2015, que altera os art's. $1^{\circ}$ ao 33 da Lei 8.408/1999, surgiu após problemas ambientais levantados pelo PMGIRSF, principalmente no que tange a inexistência de procedimentos específicos e penalidades aplicáveis, verificando a necessidade de revisão da legislação até então vigente para a melhor efetivação na sua execução.

Destaca-se que enquanto a legislação paulista considera os RSCC em quilogramas por dia, a de Fortaleza os define por aquele gerador de volume igual ou superior a 50 litros por dia, se tornando parâmetros totalmente diferentes já que esses resíduos apresentam uma alta densidade aparente média, na ordem de cerca de $1300 \mathrm{~kg} / \mathrm{m}^{3}$, segundo AMAJU (2016). Logo, os $50 \mathrm{~kg}$ da legislação paulista equivalem a $38,46 \mathrm{~L} / \mathrm{d}$, e os $50 \mathrm{~L} / \mathrm{d}$ a $65 \mathrm{~kg} / \mathrm{d}$.

A legislação de Brasília (DF), Decreto $n^{\circ} 37.568 / 2016$, que regulamenta a Lei $n^{\circ} 5.610 / 2016$ que dispõe sobre a responsabilidade dos GGRS, introduz um novo conceito em relação às demais legislações estudadas: os RS indiferenciados que podem ser compreendidos por aqueles não disponibilizados para triagem com vistas à reciclagem ou para compostagem, ou seja, de forma não seletiva.

Nessa legislação, para a coleta e transporte dos RS, os grandes geradores devem contratar empresa previamente cadastrada no órgão competente municipal ou através de serviço próprio, ou, ainda, firmar contrato com o órgão municipal responsável pelos serviços de limpeza urbana mediante o pagamento de preços públicos. Em contrapartida, àqueles que segregarem os RSR's poderão acondicionálos para coleta pública sem a cobrança de taxas.

Tal medida, notoriamente, se trata de um incentivo à coleta seletiva, tendo em vista que com o aumento da segregação dos materiais na sua origem os resíduos indiferenciados tenderão a diminuir seu volume e posteriormente as empresas deixarão de serem consideradas grandes geradoras.

A Lei Complementar nº 952/2016, do município de Santos (SP), introduz uma abordagem não vista nas demais: os Grandes Geradores Domésticos (GGD), definidos por àqueles provenientes de condomínios de edifícios residenciais ou de uso misto, cuja soma dos RS não perigosos, disponibilizados para Triagem com vistas à reciclagem e/ou para compostagem, ultrapasse, em volume diário, 200 
(duzentos) litros ou $120 \mathrm{~kg}$ por dia. Os geradores de volume inferior a este são caracterizados por Pequeno Gerador Doméstico. Ambos devem implementar a segregação dos resíduos na fonte, em RSR's, RO's, resíduos não recicláveis e rejeitos, no entanto poderão utilizar o serviço público de coleta sem a previsão de pagamento de preços públicos.

\subsection{Projeção de Cenário para Juazeiro do Norte}

Atualmente no município de Juazeiro do Norte (CE), o Sistema de Limpeza Pública municipal coleta os resíduos domiciliares e de característica domiciliar resultantes de estabelecimentos comerciais, de prestação de serviço, públicos, institucionais, dentre outros enquadrados na Classe II - Não perigosos pela NBR 10004:2004 da ABNT, independente do volume ou quilograma diário gerado, exceto aqueles empreendimentos que o órgão ambiental competente entende, a partir da emissão da Licença Ambiental, que são responsáveis por destinar seus resíduos de forma independente a coleta pública municipal. E ainda, os RSCC e Resíduos de Poda e Jardinagem que possuem regulamentação própria pelo Decreto Municipal $n^{\circ}$ $226 / 2016$.

No entanto, apesar do Decreto Municipal n 226/2016 estabelecer que o gerador de resíduos de poda e limpeza de jardins com volume acima de 0,3 $\mathrm{m}^{3}$ é responsável pela sua remoção e destinação final ambientalmente adequada por empresas licenciadas pelo órgão competente, atualmente o município executa esse tipo de coleta sem a cobrança de taxas específicas, uma vez que, na tentativa de aplicá-las e na exigência do cumprimento do referido decreto houve manifestações da população em desfavor as determinações.

As legislações municipais existentes não instituem especificamente normas de responsabilidade sobre os GGRS, bem como previsões de cobrança de taxas dos serviços de limpeza pública prestados. Essa realidade levou a um investimento no ano de 2017, em média, de cerca de R\$ 22 milhões para execução de todos os serviços de limpeza urbana no município, segundo o Portal da Transparência. Esse valor equivale a um recurso aplicado de aproximadamente $\mathrm{R} \$ 7,79$ mensais por 
habitante urbano, que, segundo dados do Panorama de RS da ABRELPE (2016), da média nacional dos recursos aplicados nesses serviços, cerca de 60,2\% correspondem aos serviços de Coleta dos RSU.

Com o objetivo de construir uma referência da geração de RS de determinadas atividades no município de Juazeiro do Norte (CE) e se ter noção das frações recicláveis e aquelas que iriam para a coleta pública, estruturou-se a Tabela 01, discriminando os valores em quilograma e volume diários gerados por empreendimentos de diferentes portes e que desempenham papel importante na economia do município em questão.

Tabela 01 - Referência de geração de RS de determinadas atividades no município de Juazeiro do Norte - CE

\begin{tabular}{|c|c|c|c|c|c|}
\hline & $\begin{array}{c}\text { Porte do } \\
\text { Empreendimento }^{4}\end{array}$ & $\begin{array}{l}\text { Tipos de } \\
\text { Resíduos }\end{array}$ & Transportadora & $\begin{array}{l}\text { Total } \\
(\mathrm{kg} / \mathrm{d})\end{array}$ & $\begin{array}{l}\text { Total } \\
(\mathrm{L} / \mathrm{d})\end{array}$ \\
\hline \multirow{4}{*}{$\begin{array}{l}\text { SUPERMERCADO } \\
01^{1}\end{array}$} & \multirow{4}{*}{ GRANDE } & RO's & CPM & 45,67 & 37,66 \\
\hline & & RSR's & $\mathrm{EP}$ & 90,91 & 277,80 \\
\hline & & Outros & CPM & 0,8 & 3,33 \\
\hline & & TOTAL & & 137,38 & 318,79 \\
\hline \multirow{4}{*}{$\begin{array}{l}\text { SUPERMERCADO } \\
02^{1}\end{array}$} & \multirow{4}{*}{ MÉDIO } & RO's & CPM & 32,33 & 26,65 \\
\hline & & RSR's & EP & 131,14 & 407,87 \\
\hline & & Outros & CPM & 0,6 & 2,5 \\
\hline & & TOTAL & & 164,08 & 437,02 \\
\hline \multirow{3}{*}{$\begin{array}{c}\text { COMÉRCIO } \\
\text { ATACADISTA } 01\end{array}$} & \multirow{3}{*}{ EXCEPCIONAL } & RO's & \multirow{2}{*}{ EP } & 245,57 & 202,45 \\
\hline & & RSR's & & 132,19 & 447,82 \\
\hline & & TOTAL & & 377,76 & 650,27 \\
\hline \multirow{3}{*}{ HOTELARIA $01^{1}$} & \multirow{3}{*}{ MÉDIO } & RO's & CPM & 0,167 & 0,14 \\
\hline & & RSR's & EP e CPM & 1,35 & 9,30 \\
\hline & & TOTAL & & 1,517 & 9,44 \\
\hline \multirow{3}{*}{ HOTELARIA $02^{2}$} & \multirow{3}{*}{ GRANDE } & RO's & EP & 205,71 & 482 \\
\hline & & RSD & CPM & - & 514 \\
\hline & & TOTAL & & 205,71 & 996 \\
\hline IES $01^{3}$ & EXCEPCIONAL & $\begin{array}{l}\text { Resíduo } \\
\text { Comum }\end{array}$ & CPM & - & $\begin{array}{c}5.140,8 \\
7\end{array}$ \\
\hline IES $02^{3}$ & EXCEPCIONAL & $\begin{array}{l}\text { Resíduo } \\
\text { Comum }\end{array}$ & CPM & - & 789,77 \\
\hline CRV $^{6}$ & EXCEPCIONAL & RSD & $\mathrm{CPM}^{5}$ & $223,04^{\prime}$ & $\begin{array}{c}1218,8 \\
0^{\prime}\end{array}$ \\
\hline
\end{tabular}




\section{$\mathrm{CRH}^{7}$}

EXCEPCIONAL

RSD

CPM $^{5}$

114,39

$598,90^{\prime}$

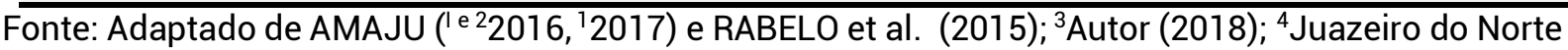
(2011, Anexo II); ${ }^{5}$ Informação fornecida pela empresa prestadora dos serviços de limpeza pública.

Nota: Para converter os dados de quilograma/dia, disponibilizados nos PGRS's e estudos analisados, para litros/dia utilizou-se as respectivas Densidades Aparente Média $\left(\mathrm{kg} / \mathrm{m}^{3}\right)$ dispostas no estudo de SILVA e SANTOS (2010); ${ }^{3}$ Instituição 01: 3.759 alunos e Instituição 02: 1497 alunos; ${ }^{6}$ Média de 91 apartamentos; ${ }^{7}$ Média de 47 casas.Nota: RSD - Resíduos Sólidos Domésticos; IES - Instituição de Ensino Superior; CPM - Coleta Pública Municipal; EP - Empresa Privada.

Observa-se que, independente do volume diário de resíduos gerados, a maioria dos empreendimentos são atendidos pela Coleta Pública Municipal, atribuindo atenção especial aos RO's e RSR's, uma vez que esses podem ser facilmente reciclados através da adoção da segregação dos materiais na origem.

Os supermercados selecionados, por exemplo, apresentam uma representatividade em volume (L/d) dos RSR's, em média, de 90,23\% do total. $E$, apesar de esses destinarem a empresas de reciclagem, outros que não possuem licenciamento ambiental talvez não o façam pela ausência de regulamentação específica e consequente fiscalização.

Observa-se também, de forma a enfatizar a necessidade desse tipo de regulamentação aliada a programas de coleta seletiva, o grande volume gerado pela IES 01 , de cerca de 5.140,87 L/d, contribuindo com aproximadamente $11 \mathrm{~m}^{3}$ de resíduo a cada coleta pública municipal ao tempo que poderia estar sendo realizada a segregação desses materiais na sua origem e destinados as Associações de Catadores existentes no município em cumprimento ao que preconiza a PNRS. 0 mesmo é valido para os resíduos provenientes da atividade de Hotelaria 02, na qual certamente apresenta uma proporção de mais de 50\% de RSR's, conforme dados de representatividade da AMAJU (2016).

Salientando que, segundo Tabela 01, os empreendimentos comerciais geram em média cerca de 470 litros de RS diariamente.

Isto posto, diferentemente da legislação de Brasília (DF) que define os GGRS em cima dos quantitativos de RS Indiferenciáveis, propõe-se para o município de Juazeiro do Norte, a definição a partir dos Resíduos Não Perigosos da Classe II - A da NBR 10004:2004 da ABNT em sua totalidade, ou seja, em cima da produção total de resíduos, visando obter um maior controle sobre os resíduos gerados e, por 
regulamentação específica e em conjunto a que se discute no presente trabalho, incentivar a implementação da Coleta Seletiva na origem e Logística Reversa.

Uma alternativa para classificação dos GGRS seria através do peso específico dos RS gerados, o qual dado em $\mathrm{kg} / \mathrm{m}^{3}$ evitaria que empreendimentos que geram muito resíduo reciclável de baixa densidade sejam englobados como grande gerador apenas pelo volume. Contudo, ao se falar de disposição final ambientalmente adequada que atualmente no Brasil legalmente é o Aterro Sanitário e considerando que os servidores que executam a coleta pública dificilmente têm conhecimento técnico para assimilar densidade específica de materiais, além do custeio com equipamentos para diferenciação destes, o volume exerce preferência nesse tipo de regulamentação.

Logo, a princípio, o uso de volume se sobressai ao quilograma, principalmente, na fase de acondicionamento dos resíduos, proporcionando ao operador diferenciar visualmente, sem necessidade de balanças, os pequenos dos grandes geradores.

À vista de todo o exposto e com vista a evitar manifestações contrárias por parte de empreendimentos de pequeno a médio porte, não deixando de compreender os empreendimentos de porte igual ou superior a grande, considerando como o mais adequado a realidade juazeirense, recomenda-se que pessoas físicas ou jurídicas que produzam resíduos em estabelecimentos de uso não residenciais incluídos os estabelecimentos comerciais, de prestação de serviço, instituições de ensino, públicos ou privados, ou qualquer estabelecimento gerador, cuja natureza ou composição sejam similares àquelas dos Resíduos Sólidos Domésticos (RSD), conforme Classe II da NBR 10004:2004 ABNT, com geração diária de um volume igual ou superior a 200 L/d, seja considerada GGRS.

É válido salientar que apesar das instituições de ensino superior consideradas para o referencial apresentarem uma produção diária em volume superior aos empreendimentos comerciais não se justifica a aplicação de um parâmetro diferenciado já que não deixam de serem estabelecimentos com diferentes atividades comerciais sendo desenvolvidas em seu interior, as quais contribuem para que os resíduos gerados tomem características bem heterogêneas, enfatizando 
ainda mais a importância de tê-las como grandes geradoras em seus mais diferentes portes.

E acreditando que a partir da implantação de uma coleta seletiva eficiente ainda restem resíduos não recicláveis, misturados ou contaminados, não passíveis de separação, cabe, portanto, a inclusão destes na regulamentação em discussão determinando um limite específico para o acondicionamento e coleta pelo Sistema de Coleta Pública Municipal. Essa medida pode ser vista como um incentivo a promoção por parte do empreendimento da segregação de materiais na origem com a devida destinação as Associações/Cooperativas de Recicláveis.

Com fito de fundamentar, estruturou-se a Tabela 2 com representatividade em valores percentuais das produções em massa e volume dos resíduos gerados em empreendimentos comerciais, distribuídos em RSR's, RO's e "Outros" (resíduos de varrição, rejeitos e outros não passíveis de segregação), a fim de simular a quantidade potencial de recicláveis e os dispostos para a coleta pública.

Tabela 02 - Caracterização dos RS em valores percentuais gerados por empreendimentos comerciais

\begin{tabular}{|c|c|c|c|c|c|c|c|}
\hline & & $\begin{array}{c}\text { \% de } \\
\text { RSR's } \\
\text { em } \\
\mathrm{kg} / \mathrm{d}\end{array}$ & $\begin{array}{l}\text { \% de } \\
\text { RO's } \\
\text { em } \\
\mathrm{kg} / \mathrm{d}\end{array}$ & $\begin{array}{c}\% \text { de } \\
\text { Outros } \\
\text { kg/d }\end{array}$ & $\begin{array}{c}\% \text { de } \\
\text { RSR's } \\
\text { em L/d }\end{array}$ & $\begin{array}{c}\text { \% de } \\
\text { RO's } \\
\text { em L/d }\end{array}$ & $\begin{array}{c}\% \text { de } \\
\text { Outros } \\
\text { L/d }\end{array}$ \\
\hline \multirow{9}{*}{$\begin{array}{c}\text { Empreendime } \\
\text { ntos } \\
\text { Comerciais }\end{array}$} & $\begin{array}{c}\text { Supermercado } \\
01\end{array}$ & 66,18 & 33,24 & 0,58 & 87,14 & 11,81 & 1,05 \\
\hline & $\begin{array}{c}\text { Supermercado } \\
02\end{array}$ & 79,93 & 19,71 & 0,36 & 93,33 & 6,1 & 0,57 \\
\hline & $\begin{array}{c}\text { Loja de Móveis } \\
\text { e } \\
\text { Eletrodoméstico } \\
1\end{array}$ & 91 & 0 & 9 & 93,14 & 0 & 6,86 \\
\hline & $\begin{array}{c}\text { Ramo } \\
\text { Farmacêutico' }\end{array}$ & 59 & 18 & 23 & 66,69 & 4,47 & 28,84 \\
\hline & MÉDIA (\%) & $\begin{array}{c}74,027 \\
5\end{array}$ & $\begin{array}{c}17,737 \\
5\end{array}$ & 8,235 & 85,075 & 5,595 & 9,33 \\
\hline & Atacadista 01 & 34,99 & 65,01 & 0 & 68,87 & 31,13 & 0 \\
\hline & Atacadista $02^{1}$ & 36 & 42 & 22 & 53,12 & 12,85 & 34,03 \\
\hline & MÉDIA (\%) & 35,495 & 54 & 11 & 60,995 & 21,99 & 17,015 \\
\hline & $\begin{array}{l}\text { Shopping } \\
\text { Center }^{1}\end{array}$ & 38,63 & 53,98 & 7,39 & 78,15 & 12,92 & 8,93 \\
\hline
\end{tabular}

Fonte: Adaptado de ${ }^{1}$ AMAJU (2016).

Nota: As demais referências foram tiradas da Tabela 01 se utilizando, inclusive, das fontes nela citadas. 
A partir do panorama geral da Tabela 2, observa-se que em volume, cerca de $11,76 \%$ dos resíduos gerados pertencem a categoria "Outros", indicando que estes seriam dispostos para a Coleta Pública Municipal (CPM). Assim, se for considerado o limite para grande gerador de 200L/d, aponta-se que 23,52L seriam de resíduos não disponibilizados para triagem com fins de reciclagem ou compostagem, mas para a coleta pública. Em quilogramas por dia, equivalem ao valor de 17,75.

Desta forma, para os resíduos resultantes mesmo após a segregação destes em resíduos recicláveis e orgânicos, ou seja, os resíduos não recicláveis, seja permitido o seu acondicionamento à CPM, em volume diário de até $100 \mathrm{~L}$ para o primeiro ano de implementação da regulamentação, dando a oportunidade de adaptação aos empreendimentos.

Essa medida irá permitir que estabelecimentos não enquadrados pelo volume diário de 200L, geradores de 100 a 200L, comecem a diferenciar seus RSR's na fonte e destiná-los as associações de catadores devidamente licenciadas, pois assim teriam um volume de resíduos não-recicláveis inferior ao prescrito, uma vez que para volumes diários superiores considerar-se-ia da mesma forma como um GGRS e este deverá se responsabilizar pelo gerenciamento integral de seus resíduos, podendo recorrer à contratação de empresas terceirizadas, ou mediante ao pagamento de taxas para a prefeitura.

Não obstante ao exposto, o ideal é que o limite de volume prescrito para os resíduos não-recicláveis diminua com o decorrer dos anos, conforme o processo de coleta seletiva é executado nesses estabelecimentos, objetivando atingir o valor considerado mais adequado, de acordo com a Tabela 2, de 25L/d, a julgar que uma residência no município de Juazeiro do Norte (CE) produz em média, cerca de 10L/d de resíduos não diferenciados, segundo dados da AMAJU (2016) e considerando três moradores por unidade familiar.

Quanto aos Condomínios Residenciais, apesar de gerarem resíduos restritamente domiciliares, consistem em diversas estruturas que abrigam diferentes pessoas com os mais diversos padrões de consumo e que desempenham diferentes tipos de atividades em uma área territorial muitas vezes pequena. Essa realidade, 
consequentemente, contribui para a heterogeneidade dos resíduos gerados nestes locais (Araújo, 2016).

Dados fornecidos pela AMAJU (2017) demonstram que entre os anos de 2015 a 2017 foram protocolados 18 novos processos de Licença Ambiental para instalação de Condomínios Multifamiliares com Infraestrutura no município de Juazeiro do Norte. Desta forma, ao considerar os condomínios residenciais como GGRS o município visualiza a oportunidade de incluir as práticas de coleta seletiva nessas unidades, já que esta necessita de tempo e planejamento para se tornar efetiva.

E apesar de o enquadramento desses empreendimentos como GGRS não ser previsto na PNRS, a PNSB institui a possibilidade de aplicação de taxas ou tarifas e outros preços públicos para sustentabilidade econômica do sistema. Salientando-se que o principal objetivo em sugerir o enquadramento dessas unidades é o incentivo do processo de Coleta Seletiva no município em estudo com vistas a sua posterior universalização.

Desta forma, propõem-se atribuir preços públicos para a coleta, transporte e destinação final dos resíduos provenientes dos Condomínios Residenciais e de uso Misto que gerem um volume diário igual ou superior a 1000 litros, dado que a média calculada de geração entre Condomínio Residencial Vertical (CRV) e Condomínio Residencial Horizontal ( $\mathrm{CRH}$ ) é de 908,85 litros por dia. Tal medida deve vir acompanhada do devido cadastramento ao órgão ambiental competente, a apresentação de PGRS e obrigatoriedade de implantação da Coleta Seletiva.

Destaca-se que para os condomínios de uso misto seja estabelecido o acondicionamento diferenciado dos resíduos provenientes das unidades residências.

Segundo dados do Diagnóstico de RS (AMAJU, 2016), cerca de 34,84\% dos RSD, em volume, são de "Outros" - resíduos de varrição, rejeitos e outros não passíveis de segregação. Sabendo-se que esta parcela pode ser menor uma vez que possuíam parte dos recicláveis contaminados em decorrência da não segregação na origem, a caráter de incentivo, pode-se isentar essas unidades do preço público para coleta de resíduos "Outros" produzidos em volume diário de até 300 litros, considerando que os RSR's devem ser destinados prioritariamente às associações de catadores. 
Ainda, sugere-se a abrangência de feiras livres em regulamentação própria, uma vez que no Código de Postura do município - Lei Complementar n ${ }^{\circ}$ 10/2006, em seu art. 67, inciso IV, está prescrito que o Poder Executivo deve organizar e instituir preceitos de higiene e limpeza pública para as feiras livres municipais, determinando inicialmente que os feirantes devem dispor de recipientes para o acondicionamento dos RS resultantes das suas vendas se adequando, a princípio, a separar o resíduo seco do úmido, bem como manter o entorno de suas barracas limpo.

Vale lembrar que Juazeiro é uma cidade de romarias, as quais são responsáveis pelo aumento considerável da população e de comércios ambulantes e eventuais em vias, logradouros e espaços públicos nos períodos das festas religiosas ocasionando impactos ao meio ambiente urbano, em especial na geração de Resíduos Sólidos Urbanos (RSU) descartados irregularmente em vias e logradouros públicos (Pereira, 2013).

Quanto a eventos realizados em vias, logradouros ou espaços públicos, adotando como referência a Lei Distrital $n^{\circ}$ 5.610/2016, propõe-se a diferenciação dos promotores de eventos com fins lucrativos como responsáveis pelos resíduos gerados direta ou indiretamente à realização do evento, devendo estes apresentar juntamente à documentação exigida para emissão de Autorização de Uso do Som ou Autorização de Uso do Espaço Público ou, ainda, por cadastro específico para tal fim - a critério do Poder Público municipal - um Plano Simplificado de Gerenciamento de RS priorizando a coleta seletiva, conforme Figura 02. 0 mesmo é válido para as áreas circunvizinhas de eventos privados realizados em prédios ou espaços fechados de propriedade privada. 
Figura 2 - Fluxograma de proposta para Gestão de RS em Eventos

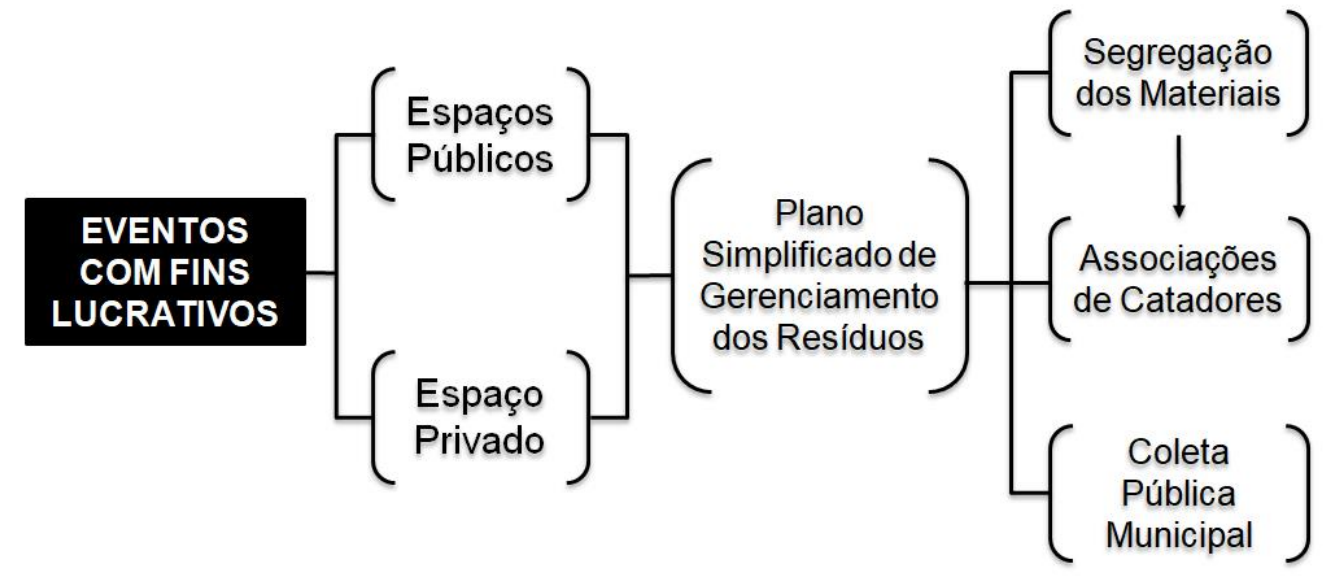

Fonte: Autor (2018).

Tal medida se faz necessário, uma vez que em sua maioria os resíduos gerados nesses eventos são RSR's. Normalmente esses resíduos são recolhidos por catadores autônomos ambulantes de forma pouco digna, logo com a coleta e acondicionamento destes de forma previamente segregada pode-se destiná-los diretamente às associações/cooperativas de catadores.

\subsubsection{Os Resíduos da Construção Civil como Grandes Geradores}

Conforme observado no Quadro 01, a Lei n 4.704/2011, que dispõe sobre a gestão integrada de RSCC e de resíduos volumosos no Distrito Federal, determina que, em qualquer que seja o volume, os geradores são responsáveis pela sua segregação, acondicionamento, coleta, transporte, tratamento, transbordo, manejo e destinação final. No entanto, os subdivide em pequenos e grandes geradores respectivamente, volumes até e superiores a $1 \mathrm{~m}^{3}$ por descarga, podendo os pequenos geradores destinar seus resíduos à rede de PEV. Essa medida pode ser vista como uma alternativa para manter o controle e a fiscalização sobre os resíduos provenientes dos pequenos geradores, ao tempo que aumenta as chances de se evitar manifestações contrárias dos munícipes.

Do mesmo modo, o Decreto de Juazeiro do Norte de $n^{\circ}$ 226/2016 considera que todo gerador, em qualquer quantidade ou volume, é responsável pelo seu gerenciamento, no entanto, sem a previsão de alguma medida de controle sobre os pequenos geradores, conforme pode ser observado na Figura 3. 
Figura 3 - Logística atual da Gestão de RSCC em Juazeiro do Norte

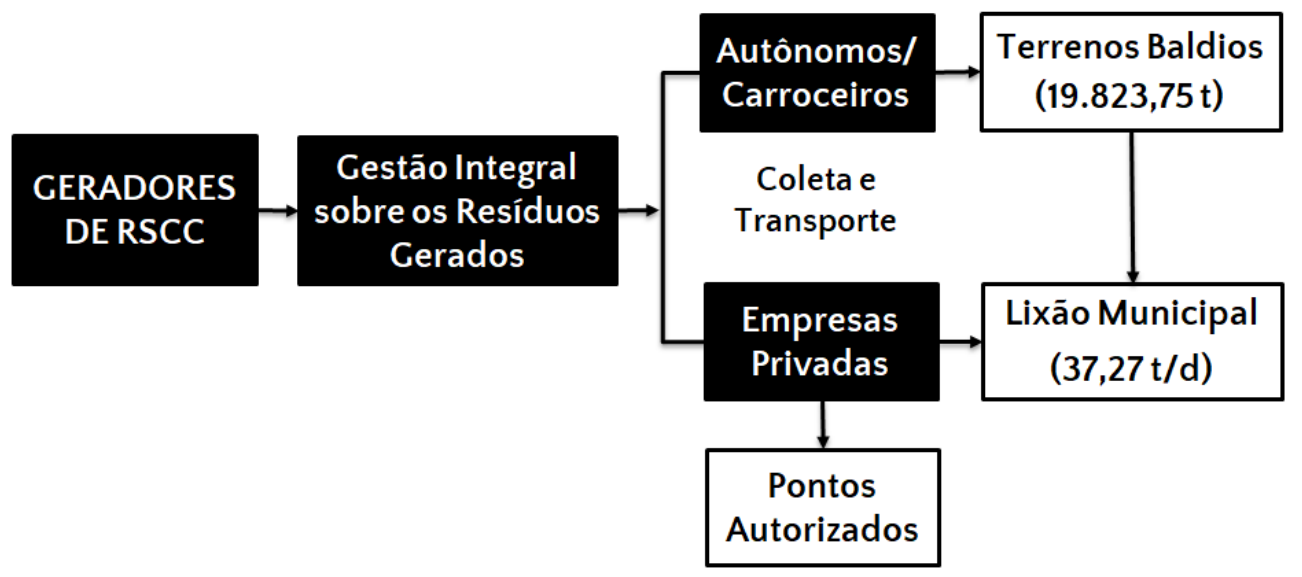

Fonte: Autor (2018).

Segundo o Diagnóstico de RS de Juazeiro do Norte (AMAJU, 2016), dos RSCC gerados que se pode ter um controle são coletados diariamente um total de 37,27 toneladas, e aqueles que não se sabe a procedência, encontrados em pontos transitórios e de disposição final inadequada, apresentam um acúmulo de cerca de 20 toneladas até o ano do estudo. Esses pontos transitórios e de disposição final inadequada, em sua maioria, são abastecidos pelas atividades dos carroceiros que, em média, coletam entre 30 a 70 vezes por semana. E a partir de entrevistas com os próprios carroceiros, o estudo relata que cerca de $80 \%$ destes informaram receber uma maior demanda para coleta e transporte de entulhos, seguido de poda.

Desta forma, orienta-se a sua revisão com vista a discriminar Pequenos dos Grandes geradores de RSCC (Figura 4), introduzindo "Ecopontos" ou PEV distribuídos estrategicamente no município objetivando evitar que os pequenos geradores destinem seus resíduos para pontos irregulares ou até mesmo que sejam acondicionados para a coleta pública municipal. 0 valor é proposto a partir do volume que normalmente é transportado por carroceiros, de 0,6 a 1,2 $\mathrm{m}^{3}$, conforme AMAJU (2016). 
Regulamentação dos grandes geradores de resíduos sólidos em Juazeiro do Norte-CE: avaliação e propostas

Figura 4 - Logística proposta para Gestão de RSCC em Juazeiro do Norte

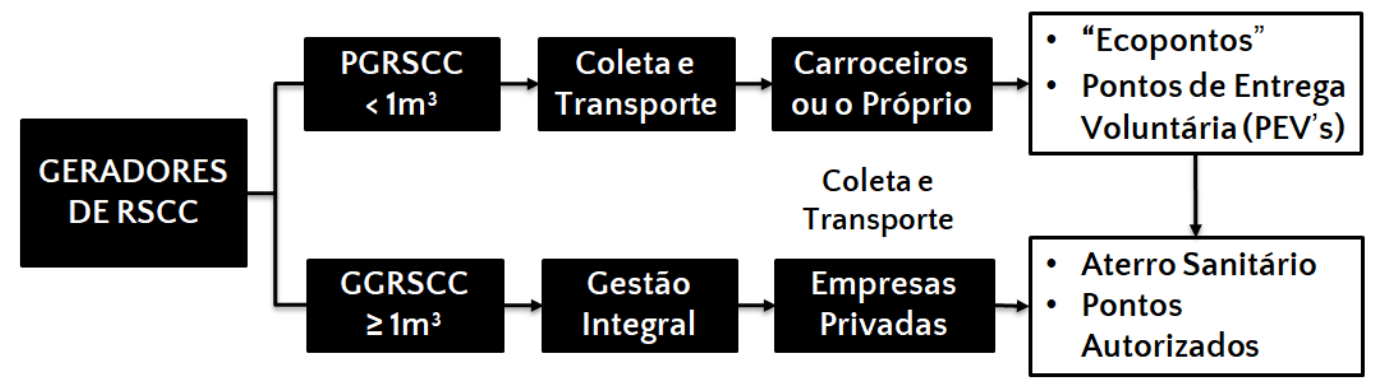

Fonte: Autor (2018).

Também é válido destacar que no município em estudo a atividade de carroceiros como coletores independentes é tradição municipal, com um número estimado de aproximadamente 1.000 a 1.500 veículos de tração animal (carroças), utilizados como instrumento de trabalho para coleta e transporte de resíduos e que, recentemente (12/03/2018), a SEMASP tomou a iniciativa de cadastrar e emplacar os carroceiros com vista a ter um maior controle e fiscalização mais efetiva. (JUAZEIRO, 2018).

Por conseguinte, sabendo-se que o município de Juazeiro do Norte (CE) possui um mercado imobiliário crescente, sugere-se ainda a elaboração de um Plano Municipal de Gerenciamento de Resíduos de Construção Civil, conforme já é previsto na Resolução CONAMA nº 307 de 2002.

Em conclusão, constrói-se o Quadro 04, resumindo as propostas acima elencadas demonstrando as categorias e seus respectivos parâmetros.

Quadro 02 - Quadro Resumo das propostas para regulamentação dos GGRS do município de Juazeiro do Norte (CE)

\begin{tabular}{|c|c|c|c|c|}
\hline $\begin{array}{c}\text { Pessoa Física ou } \\
\text { Jurídica }\end{array}$ & $\begin{array}{c}\text { Classificação } \\
\text { dos RS }\end{array}$ & $\begin{array}{l}\text { GGRS } \\
(L / d)\end{array}$ & $\begin{array}{c}\text { Manejo dos } \\
\text { RS }\end{array}$ & Obrigações com prazos \\
\hline \multirow{4}{*}{$\begin{array}{l}\text { Não residenciais } \\
\text { incluídos os } \\
\text { comerciais, de } \\
\text { prestação de serviço, } \\
\text { instituições de ensino, } \\
\text { públicos ou privados, } \\
\text { dentre outros }\end{array}$} & Classe II & $\geq 200$ & \multirow{4}{*}{$\begin{array}{l}\text { Regime } \\
\text { Privado }\end{array}$} & \multirow{6}{*}{$\begin{array}{l}\text { - Cadastrar-se junto ao } \\
\text { órgão ambiental } \\
\text { competente } \\
\text { - Executar coleta seletiva } \\
\text { interna } \\
\text { - Elaborar PGRS } \\
\text { - Manter } \\
\text { atualizados dados } \\
\text { disponíveis sempre que } \\
\text { preciso }\end{array}$} \\
\hline & RSCC & $\begin{array}{l}> \\
1000\end{array}$ & & \\
\hline & Resíduos & $>100^{\prime}$ & & \\
\hline & $\begin{array}{l}\text { Nao } \\
\text { Recicláveis }\end{array}$ & $>25^{\prime \prime}$ & & \\
\hline \multirow{2}{*}{$\begin{array}{l}\text { Condomínios } \\
\text { residenciais ou de uso } \\
\text { Misto }\end{array}$} & Classe II & $\begin{array}{l}\geq \\
1000\end{array}$ & \multirow{2}{*}{$\begin{array}{l}\text { Regime } \\
\text { Público } \\
\text { com } \\
\text { cobrança } \\
\text { de taxas }\end{array}$} & \\
\hline & $\begin{array}{l}\text { Resíduos } \\
\text { Não } \\
\text { Recicláveis }\end{array}$ & $>300$ & & \\
\hline
\end{tabular}

Fonte: Autor (2018). 
Nota: 'Por tempo proposto em no máximo de um ano; "Valor considerado ideal após o efetivo processo de coleta seletiva a ser executado pelos GGRS.

É válido destacar que a não abordagem de indústrias no presente trabalho justifica-se por esse tipo de atividade já estar incluída na PNRS como responsável integral pelo gerenciamento dos seus resíduos, seja ele em qualquer quantidade ou volume. Todavia, deve-se deixar claro essa condição na presente regulamentação.

\section{CONSIDERAÇÕES FINAIS}

Através da compilação das legislações existentes extraímos o quão peculiar são as discussões acerca da Gestão de RS ao tempo que se destaca a significância da elaboração de um Plano de Gestão Integrada de Resíduos Sólidos por técnicos devidamente capacitados como ferramentas fundamentais para construção desse tipo de regulamentação. E, se elaborado a nível regional, favorece a viabilidade econômico-financeira para sua execução a partir dos Consórcios Públicos.

Notoriamente, com essa regulamentação se vislumbra a oportunidade de implementar a coleta seletiva aliada a logística reversa, visando a sua posterior expansão para os diversos agentes envolvidos no ciclo de vida do produto. Ademais, o exemplo de São Paulo no que tange a organização das feiras livres deve ser considerado para a realidade juazeirense, com vista a revitalizar a gestão de RS dessas áreas e, principalmente, nos mercados públicos uma vez que possuímos um dos maiores fornecedores de hortifrutigranjeiro da região do Cariri com alto potencial gerador de RO's ideais para produção de adubos orgânicos através da compostagem.

Enfim, Juazeiro do Norte (CE), como município central tanto em localização territorial como na economia da RMC tem o dever moral e ético de servir de exemplo para os demais no que tange ao gerenciamento de RS. E, atualmente, com a instalação de dois novos aterros sanitários privados, a adequação a esse novo paradigma é fundamental e necessária através de políticas públicas ou iniciativa privada e direcionando apenas os resíduos não recicláveis e rejeitos para os aterros contribuindo assim para sua vida útil. Sabe-se que esse processo não é simples e 
rápido de ser efetivado, principalmente por instabilidades políticas, mas adotandose iniciativas de forma gradativa, a começar pelos GGRS, aumentam-se as possibilidades.

Dada a importância do assunto, recomenda-se a realização de futuros trabalhos firmando parcerias entre o ambiente acadêmico e os órgãos públicos para desenvolver estudos aplicados a melhoria do Planejamento Ambiental Urbano dos municípios, bem como expandir a coleta seletiva para pequenos geradores e unidades residenciais. O Plano Regional de Coleta Seletiva para a Região do Cariri já está pronto, restando agora iniciativa dos gestores públicos em implantá-la e o apoio acadêmico ao diagnosticaras principais dificuldades na execução de uma coleta seletiva, bem como, desenvolver programas de educação ambiental junto às populações através de escolas, centros de referência e assistência social, dentre outros, e buscando a consolidação das associações de catadores.

\section{REFERÊNCIAS}

ASSOCIAÇÃO BRASILEIRA DE NORMAS TÉCNICAS. ABNT. NBR 10004: Resíduos Sólidos - Classificação. Rio de Janeiro, RJ, 2004.

ARAUJO, S. Gestão de Resíduos Sólidos em Condomínios Residenciais. Portal Resíduos Sólidos, 2016. Disponível em: https://portalresiduossolidos.com/gestaode-residuos-solidos-em-condominios-residenciais/. Acesso em: 20 jan. 2018.

AMAJU. Diagnóstico de Resíduos Sólidos do Juazeiro do Norte (CE). In: Praticas Projetos e Consultoria LTDA e EnviTeSB LTDA - Portal de Resíduos Sólidos. Juazeiro do Norte, 2016.

AMAJU. Planos de Gerenciamento de Resíduos Sólidos de empresas licenciadas e em processo de Licenciamento. Cópia Impressa. Disponibilizados em 2017.

ABRELPE. Panorama de Resíduos Sólidos no Brasil. 2016. Disponível em: http://www.abrelpe.org.br/Panorama/panorama2016.pdf. Acesso em: 02 nov. 2017.

BELÉM (Município). Decreto n 83.021, de 19 de junho de 2015. Estabelece normas e prazo para o cadastramento dos Grandes Geradores de Resíduos Sólidos, dispõe sobre as ações fiscalizatórias a serem adotadas nos casos de infração à Lei $n^{\circ}$ 12.305, de 2 de agosto de 2010, que instituiu a Política Nacional de Resíduos Sólidos, bem como às normas nacionais e municipais que tutelam a proteção ao meio ambiente e à saúde pública, e dá outras providências. Ano LVI - No 12.832, Diário Oficial do Município, 22 jun. 2015. p. 2-3. 
BRASIL. Câmara dos Deputados. Projeto de Lei $\mathbf{n}^{\circ}$ 5.739, de 2016. Acrescenta os artigos 13, III, 20, "c", parágrafo único ao art. 28 e parágrafo único ao art. 60 à Lei 12.305(Política Nacional de Resíduos Sólidos), de 2 de agosto de 2010, para incluir os resíduos extraordinários. Aguardando Parecer do Relator na Comissão de Meio Ambiente e Desenvolvimento Sustentável (CMADS). Disponível em:

http://www.camara.gov.br/proposicoesWeb/prop_mostrarintegra;jsessionid=B3462 E44CE81CAB9E1F57B227CFE7C0C.proposicoesWebExterno2?codteor $=1474211 \&$ fil ename $=P L+5739 / 2016$. Acesso em: 22 fev. 2018.

BRASIL. Lei $\mathbf{n}^{\circ}$ 11.445, de 05 de janeiro de 2007. Estabelece diretrizes nacionais para o saneamento básico; altera as Leis nos 6.766, de 19 de dezembro de 1979, 8.036, de 11 de maio de 1990, 8.666, de 21 de junho de 1993, 8.987, de 13 de fevereiro de 1995; revoga a Lei no 6.528, de 11 de maio de 1978; e dá outras providências. Presidência da República, 2007. Disponível em:

http://www.planalto.gov.br/ccivil_03/_ato2007-2010/2007/lei/l11445.htm. Acesso em: 09 dez. 2017.

BRASIL. Lei n 12.305, de 02 de agosto de 2010. Institui a Política Nacional de Resíduos Sólidos; altera a Lei no 9.605, de 12 de fevereiro de 1998; e dá outras providências. Diário Oficial da República Federativa do Brasil. Brasília, DF, 3agost. 2010. Disponível em: http://www.mma.gov.br/port/conama/legiabre.cfm?codlegi=636. Acesso em: 09 dez. 2017.

BRASÍLIA. Lei n 4.704, de 20 de dezembro de 2011. Dispõe sobre a gestão integrada de resíduos da construção civil e de resíduos volumosos e dá outras providências. Distrito Federal, DF, 2011. Disponível em:

http://www.sema.df.gov.br/wp-conteudo/uploads/2017/09/Lei-Distrital-nº-4.704de-2011.pdf. Acesso em: 20 dez. 2017.

BRASÍLIA. Decreto n $^{\circ}$ 37568, de 24 de agosto de 2016. Regulamenta a Lei $n^{\circ}$ 5.610, de 16 de fevereiro de 2016, altera o Decreto $n^{\circ} 35.816$, de 16 de setembro de 2014, e dá outras providências. 161. ed. Diário Oficial do Distrito Federal, DF, 25 ago. 2016. p. 3-5.

DEMAJOROVIC, J. Da política tradicional de tratamento do lixo à política de gestão de resíduos sólidos: As novas prioridades. Revista de Administração de Empresas São Paulo, v. 35, n.3, p. 88-93, Mai./Jun. 1995.

FORTALEZA (Município). Lei $\mathbf{n}^{\circ} \mathbf{1 0 3 4 0}$, de 28 de abril de 2015. Altera os arts. $1^{\circ}$ ao 33 da Lei 8.408, de 24 de dezembro de 1999, e dá outras providências. Diário Oficial do Município, Fortaleza, CE, 08 mai. 2015. 
JUAZEIRO DO NORTE. SEMASP inicia cadastramento de carroceiros. Imprensa, 2018. Disponível em: http://www.juazeiro.ce.gov.br/Imprensa/Noticias/2018-0313-Semasp-inicia-cadastramento-de-carroceiros-4347/. Acesso em: 04 abr. 2018.

JUAZEIRO DO NORTE. Lei Complementar $n^{\circ}$ 10, de 19 de maio de 2006. Código de Posturas do Município de Juazeiro do Norte. 2006. Disponível em:

http://www2.juazeiro.ce.gov.br/Legislacao/LEI\%20COMPLEMENTAR\%20102006.pdf. Acesso em: 20 jan. 2018.

JUAZEIRO DO NORTE. Decreto $\mathbf{n}^{\circ}$ 226, de 21 de janeiro de 2016. Regulamenta a Lei $\mathrm{n}^{\circ} 3689$, de 28 de maio de 2010 no que tange a coleta, armazenamento, transporte e disposição final de resíduos de construção civil e outros resíduos não abrangidos pela coleta regular e dá outras providências. № 4179, Diário Oficial do Município, 25 jan. 2016. p. 1-5.

LEITE, R. Incentivos legais de Juazeiro do Norte-CE. Portal de Resíduos Sólidos,30 jan. 2017. Disponível em: https://portalresiduossolidos.com/legislacoes-dejuazeiro-do-norte-ce/. Acesso em: 03 mai. 2018.

MACHADO, G. B. A Cobrança pela Coleta de Resíduos. Portal Resíduos Sólidos, 2014. Disponível em: http://www.portalresiduossolidos.com/cobranca-pelacoleta-de-residuos/. Acesso em: $10 \mathrm{dez} .2017$.

PEREIRA, C. M. C. Análise Socioambiental da Cidade de Juazeiro do Norte:

Subsídios para a Construção da Agenda 21 Local. 2013. Tese (Doutorado em Geociência) Universidade Estadual Paulista, Instituto de Geociências e Ciências Exatas - Rio Claro, SP, 2013.

RABELO, B.L.; ASSUNÇÃO, S. G. S.; VENTUROLI, F. Estudo Comparativo da Geração Per Capita de Resíduos Sólidos entre os Condomínios do Lago e Caraíbas, em Goiânia - Goiás. 5th International Workshop -Advances in Cleaner Production Academic Work, São Paulo, SP, 2015.

SANTOS (Município). Lei Complementar $n^{\circ}$ 792, de 14 de janeiro de 2013. Institui o Programa Municipal de Gerenciamento dos Resíduos Sólidos da Construção Civil PMGRSCC, e dá Outras Providências. Ano XXIV, Nº 5811, Diário Oficial de Santos, 15 jan. 2015.p. 9-13.

SANTOS (Município). Lei Complementar n 952, de 30 de dezembro de 2016. Disciplina o Gerenciamento dos Resíduos Sólidos que Especifica, e dá Outras Providências. Ano XXVIII, Nº 6780, Diário Oficial de Santos, 2 jan. 2017.p. 4-5.

SANTOS (Município). Decreto N $^{\circ} \mathbf{7 . 8 0 0}$, de 04 de julho de 2017. Regulamenta a Lei Complementar No 952, de 30 de dezembro de 2016, que Disciplina o Gerenciamento de Resíduos Sólidos que Especifica, e dá outras Providências. Ano XXIX, Nº 6901, Diário Oficial de Santos, 5 jul. 2017. p. 4-6. 
SÃO PAULO (Município). Lei no 13.478, de 30 de dezembro de 2002. Dispõe sobre a organização do Sistema de Limpeza Urbana do Município de São Paulo; cria e estrutura seu órgão regulador; autoriza o Poder Público a delegar a execução dos serviços públicos mediante concessão ou permissão; institui a Taxa de Resíduos Sólidos Domiciliares - TRSD, a Taxa de Resíduos Sólidos de Serviços de Saúde TRSS e a Taxa de Fiscalização dos Serviços de Limpeza Urbana - FISLURB; cria o Fundo Municipal de Limpeza Urbana - FMLU, e dá outras providências. São Paulo, SP, Disponível em:

http://www.prefeitura.sp.gov.br/cidade/secretarias/upload/arquivos/secretarias/fi nancas/legislacao/Lei-13478-2002.pdf. Acesso em: 09 dez. 2017.

SANTOS (Município). Lei $\mathrm{n}^{\circ} \mathbf{1 4 . 9 7 3}$, de 11 de setembro de 2009. Dispõe sobre a organização de sistemas de coleta seletiva nos Grandes Geradores de Resíduos Sólidos do Município de São Paulo e dá outras providências. Diário Oficial do Município. São Paulo, SP, 12 set. 2009. n. 170.

SILVA, M. C. da; SANTOS, G. O. dos. Densidade Aparente de Resíduos Sólidos Recém Coletados. V CONNEPI, Maceió, AL, 2010. Disponível em: http://connepi.ifal.edu.br/ocs/index.php/connepi/CONNEPI2010/paper/view/167/1 57. Acesso em: 05 jan. 2018. 